\title{
THERMODYNAMIC ANALYSIS OF AN OVER-EXPANDED ENGINE
}

\author{
Jorge J.G. MARTINS, \\ Dept. Eng. Mecanica - Un. Minho \\ Krisztina UZUNEANU \\ Universitatea "Dunarea de Jos" of Galati \\ Bernardo Sousa RIBEIRO, \\ Universidade do Minho \\ Ondrej JASANSKY, \\ Thecnical University of Liberec
}

\begin{abstract}
When the exhaust valve of a conventional spark ignition engine opens at the end of the expansion stroke, a large quantity of high pressure exhaust gas is freed to the atmosphere, without using its availability. An engine that could use this lost energy should have a better efficiency.
\end{abstract}

The equations for an over-expanded cycle (Miller cycle) are developed in this paper, together with equations for the Otto cycle, diesel cycle and dual cycle, all at part load, so they can be compared.

Furthermore, indicated cycle thermodynamical comparisons of a S.I. engine at part load (Otto cycle at half load), a S.I. engine at WOT (with half displacement) and two over-expanded S.I. engines (with different compression strokes) are examined and compared, with the aim of extending the referred theoretical cycle comparisons.

\section{INTRODUCTION}

Spark ignition and compression ignition engines are still the main power for automotive applications. The heavy traffic in cities and the high output of their engines does not allow cars to use all the potential of their engines, working for most of the time at low loads. The standard S.l. engine that are used in cars are prepared to have the best efficiency at full load, but as they are used very often at light loads, the amount of energy lost due to this inefficiency is significant.
Special attention must then be taken in the study of the part load conditions in engines, specially for automotive applications. It will be useful to understand which is the most efficient working cycle at light and part load, so these working conditions may be used as specifications during car engine design.

The major problem of the conventional S.I. engine at part load is the throttling process and the consequential low pressure at the end of the compression stroke.

The Miller cycle is based on the Otto cycle, having an expansion stroke which is longer than the compression stroke [1]. Intake valve is kept opened during a significant part of the piston movement during compression, so that part of the mixture contained in the cylinder is sent back to the inlet manifold, allowing the reduction of mixture mass that is "trapped" in the cylinder. The volume of "trapped" mixture corresponds to the cylinder volume at the closure of the intake valve. Another way of implementing this cycle consists on closing the intake valve during the admission, long before BDC. The descent of the piston will create a depression inside the cylinder, achieving the atmospheric pressure somewhere during compression, near the position where the intake valve was closed on the downward movement of the piston.

The new developments in variable valve timing (BMW Valvetronic - [2]) and the possibility of compression ratio change (SAAB) [3] allows the Miller cycle to be used at the most effective (efficient) conditions at all times. The detailed investigation of this cycle as well as the expressions that describe it, are not matters usually 
explained in internal combustion engines literature [4]. A set of equations was developed allowing the description of the Miller cycle [5], as well as the definition of the main variables that influence its development. Equations presented herein result of the application of thermodynamic laws, without using other variables that influence the cycle performance (for example noninstantaneous combustion, heat transfer and internal friction).

\section{ENGINE GEOMETRIC PARAMETERS}

In an internal combustion engine (Figure 1) with a fixed geometry the compression ratio (here named geometric $\left.-\varepsilon_{\mathrm{g}}\right)$ is unique and defined by:

$\varepsilon_{\mathrm{g}}=\frac{\mathrm{V}_{\mathrm{BDC}}}{\mathrm{V}_{\mathrm{TDC}}}=\frac{\mathrm{V}_{5}}{\mathrm{~V}_{2}}$

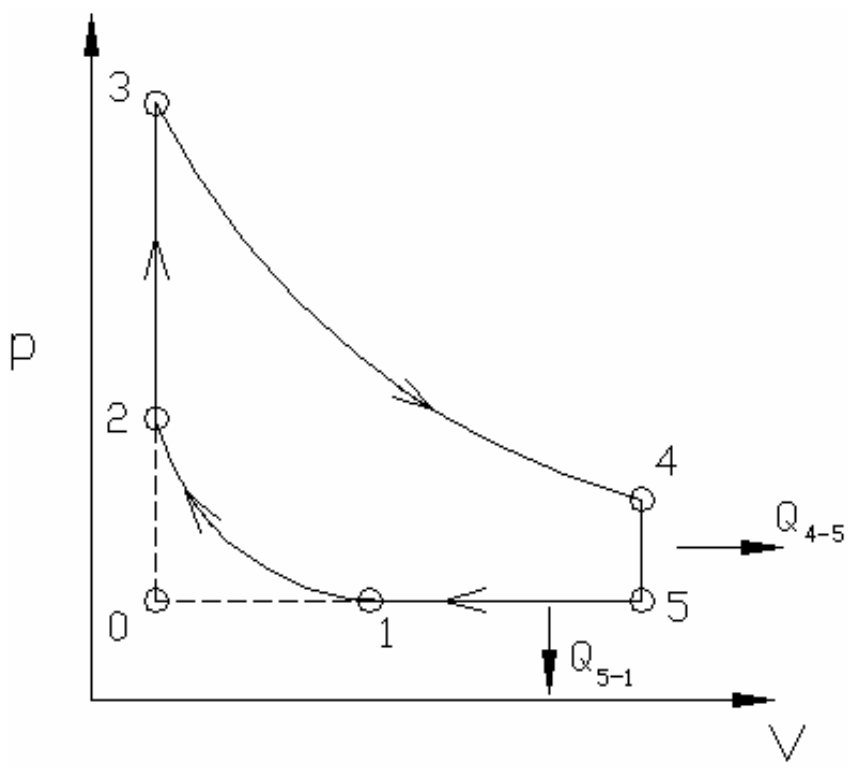

Figure $1-p-V$ diagram of a Miller cycle.

When studying the Miller cycle, due to the cycle operation (effective admission is shorter than the piston stroke), we have to consider another compression ratio that is the effective compression ratio (here named trapped $-\varepsilon_{\text {tr }}$ ). This one is defined in the same manner described in (1.1), but instead of considering the $\mathrm{V}_{\mathrm{BDC}}$, it is considered the cylinder volume at beginning of compression (where the pressure is still atmospheric). It results then:

$\varepsilon_{\mathrm{tr}}=\frac{\mathrm{V}_{\mathrm{ADM}}}{\mathrm{V}_{\mathrm{TDC}}}=\frac{\mathrm{V}_{1}}{\mathrm{~V}_{2}}$

In this kind of cycle it is necessary to enter with the relation between expansion and compression (expansion-compression ratio - $\sigma$ ), which is a characteristic parameter of the Miller cycle:

$\sigma=\frac{V_{\mathrm{BDC}}}{\mathrm{V}_{\mathrm{ADM}}}=\frac{\mathrm{V}_{5}}{\mathrm{~V}_{1}}$

From the parameters defined in (1.1) and (1.2) comes:

$\sigma=\frac{\varepsilon_{\mathrm{g}}}{\varepsilon_{\mathrm{tr}}}$

Which means that $\sigma$ also shows the relation between geometric compression ratio and the trapped compression ratio. In the Otto cycle the value of this parameter is one, since that theoretically expansion equals compression.

\section{OTTO CYCLE AT PART LOAD}

Spark Ignition engines when working at idle or at light loads usually lower the intake pressure of air to reduce load. When engines work under the Otto cycle this pressure reduction on the engine charge may be obtained by throttling, keeping the mixture at stoichiometric conditions, so that the three-way catalytic converter can work at optimal conditions. This will lead to a reduction on the intake pressure, and during the intake stroke the engine will work as an air pump. The reduction of the intake pressure leads to a reduction of the mass of air and fuel (assuming a stoichiometric mixture) trapped in the cylinder. In the $\mathrm{p}-\mathrm{V}$ diagram of this cycle (Figure 2), the pumping work (negative) is represented by the area defined by 1'-6-7-1-1' (or 5-6-7-1-5), while the positive work is $5-1$ '-2-3-4-5 (or 1-2-3-4-1).

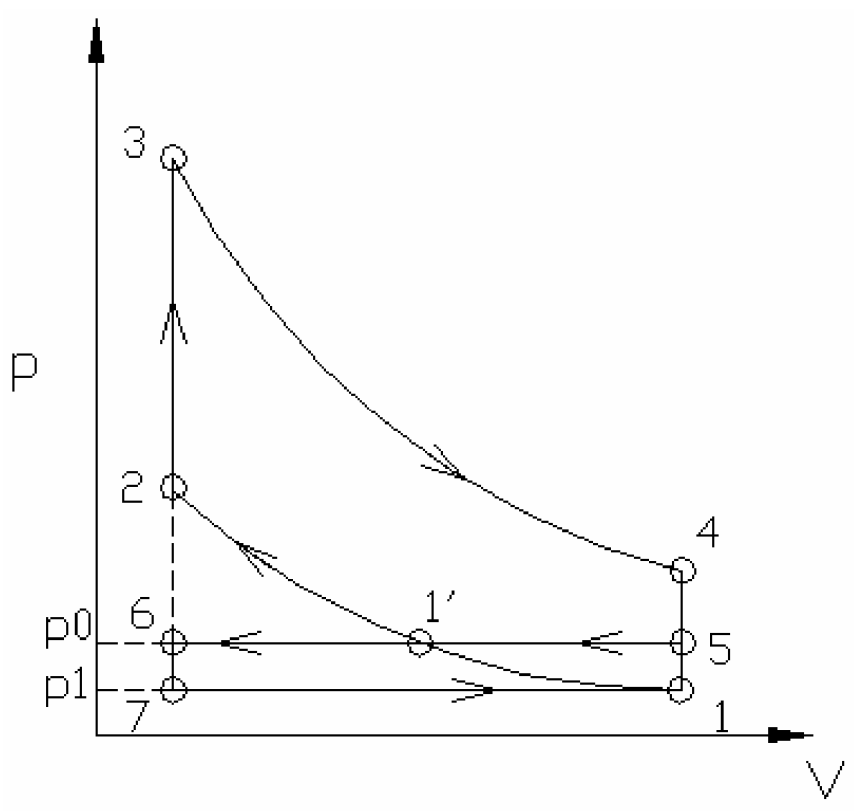

Figure 2 - $p-V$ diagram of the Otto cycle at part load. 
Analyzing the work involved in this cycle:

$\mathrm{W}=\mathrm{W}_{1^{\prime} 2}+\mathrm{W}_{34}+\mathrm{W}_{51^{\prime}}+\mathrm{W}_{1^{\prime} 6}+\mathrm{W}_{71}+\mathrm{W}_{11^{\prime}}$

All the terms will be throughoutly analyzed. The first term, which corresponds to the compression from the atmospheric pressure until $p_{2}$ is considered an isentropic process:

$\mathrm{W}_{1^{\prime} 2}=\frac{\mathrm{p}_{1^{\prime}} \cdot \mathrm{V}_{1^{\prime}}-\mathrm{p}_{2} \cdot \mathrm{V}_{2}}{\gamma-1}$

Considering:

$\mathrm{p}_{1^{\prime}}=\mathrm{p}_{0} \quad \mathrm{~V}_{1^{\prime}}=\mathrm{V}_{1}\left(\frac{\mathrm{p}_{1}}{\mathrm{p}_{0}}\right)^{\frac{1}{\gamma}} \quad \mathrm{p}_{2}=\mathrm{p}_{1} \cdot \varepsilon^{\gamma} \quad \varepsilon=\frac{\mathrm{V}_{1}}{\mathrm{~V}_{2}}$

Comes:

$\mathrm{W}_{1^{\prime} 2}=\frac{\mathrm{p}_{0} \cdot \mathrm{V}_{1}\left(\frac{\mathrm{p}_{1}}{\mathrm{p}_{0}}\right)^{\frac{1}{\gamma}}-\mathrm{p}_{1} \cdot \mathrm{V}_{1} \cdot \varepsilon^{\gamma-1}}{\gamma-1}$

For the expansion stroke, also considered an isentropic process, it comes:

$\mathrm{W}_{34}=\frac{\mathrm{p}_{3} \cdot \mathrm{V}_{3}-\mathrm{p}_{4} \mathrm{~V}_{4}}{\gamma-1}$

Considering:

$\tau=\frac{\mathrm{p}_{3}}{\mathrm{p}_{2}}=\frac{\mathrm{T}_{3}}{\mathrm{~T}_{2}} \quad \mathrm{p}_{3}=\tau \cdot \mathrm{p}_{1} \cdot \varepsilon^{\gamma} \quad \mathrm{V}_{3}=\frac{\mathrm{V}_{1}}{\varepsilon}$

The increase of temperature/pressure in combustion.

$\mathrm{Q}_{2-3}=\mathrm{m} \cdot \mathrm{c}_{\mathrm{v}} \cdot\left(\mathrm{T}_{3}-\mathrm{T}_{2}\right)=\mathrm{m}_{\mathrm{f}} \cdot \mathrm{Q}_{\mathrm{LHV}}$

It leads to:

$\tau=\frac{\mathrm{T}_{3}}{\mathrm{~T}_{2}}=1+\frac{(\gamma-1) \cdot \frac{\mathrm{m}}{1+\mathrm{A} / \mathrm{F}} \cdot \mathrm{Q}_{\mathrm{LHV}}}{\varepsilon^{\gamma-1} \cdot \mathrm{p}_{1} \cdot \Delta \mathrm{V}}=$

$=1+\frac{(\gamma-1) \cdot \mathrm{B}}{\varepsilon^{\gamma-1}}$ where: $\mathrm{B}=\frac{\frac{1}{1+\mathrm{A} / \mathrm{F}} \cdot \mathrm{Q}_{\mathrm{LHV}}}{\mathrm{R} \cdot \mathrm{T}_{1}}$ is a constant (the mixture is always stoichiometric)

$$
\mathrm{p}_{3} \cdot \mathrm{V}_{3}^{\gamma}=\mathrm{p}_{4} \cdot \mathrm{V}_{4}^{\gamma} \quad \mathrm{p}_{4}=\mathrm{p}_{3} \cdot\left(\frac{\mathrm{V}_{3}}{\mathrm{~V}_{4}}\right)^{\gamma}=\tau \cdot \mathrm{p}_{1}
$$

And the work involved in this process may be written as:

$$
\begin{aligned}
& \mathrm{W}_{34}=\frac{\tau \cdot \mathrm{p}_{1} \cdot \varepsilon^{\gamma} \cdot \frac{\mathrm{V}_{1}}{\varepsilon}-\tau \cdot \mathrm{p}_{1} \cdot \mathrm{V}_{1}}{\gamma-1}= \\
& =\frac{\tau \cdot \mathrm{p}_{1} \cdot \mathrm{V}_{1}}{\gamma-1}\left(\varepsilon^{\gamma-1}-1\right)
\end{aligned}
$$

The exhaust process is considered an isobaric process. To simplify the analysis this work was divided in two parts, from 5 to 1 ' and from 1' to 6 . Thus the work can be determined as:

$\mathrm{W}_{51^{\prime}}=\mathrm{p}_{0} \cdot\left(\mathrm{V}_{1^{\prime}}-\mathrm{V}_{5}\right)=\mathrm{p}_{0} \cdot \mathrm{V}_{1}\left[\left(\frac{\mathrm{p}_{1}}{\mathrm{p}_{0}}\right)^{\frac{1}{\gamma}}-1\right]$

And

$$
\begin{aligned}
& \mathrm{W}_{\mathrm{l}^{\prime} 6}=\mathrm{p}_{0}\left(\mathrm{~V}_{6}-\mathrm{V}_{\mathrm{1}^{\prime}}\right)=\mathrm{p}_{0}\left[\frac{\mathrm{V}_{1}}{\varepsilon}-\mathrm{V}_{1} \cdot\left(\frac{\mathrm{p}_{1}}{\mathrm{p}_{0}}\right)^{\frac{1}{\gamma}}\right]= \\
& =\mathrm{p}_{0} \cdot \mathrm{V}_{1}\left[\frac{1}{\varepsilon}-\left(\frac{\mathrm{p}_{1}}{\mathrm{p}_{0}}\right)^{\frac{1}{\gamma}}\right]
\end{aligned}
$$

The pumping work from the intake stroke can be described as an isobaric process and it becomes:

$$
\begin{aligned}
& \mathrm{W}_{71}=\mathrm{p}_{1} \cdot\left(\mathrm{V}_{1}-\mathrm{V}_{7}\right)=\mathrm{p}_{1} \cdot\left(\mathrm{V}_{1}-\frac{\mathrm{V}_{1}}{\varepsilon}\right)= \\
& =\mathrm{p}_{1} \cdot \mathrm{V}_{1}\left(1-\frac{1}{\varepsilon}\right)
\end{aligned}
$$

The first part of the compression from $p_{1}$ up to the atmospheric pressure, $p_{0}$, is described as an isentropic process. 
$\mathrm{W}_{11^{\prime}}=\frac{\mathrm{p}_{1} \cdot \mathrm{V}_{1}-\mathrm{p}_{1^{\prime}} \cdot \mathrm{V}_{1^{\prime}}}{\gamma-1}=$

$=\frac{\mathrm{p}_{1} \cdot \mathrm{V}_{1}-\mathrm{p}_{0} \cdot \mathrm{V}_{1} \cdot\left(\frac{\mathrm{p}_{1}}{\mathrm{p}_{0}}\right)^{\frac{1}{\gamma}}}{\gamma-1}$

Considering equations (2.3), (2.7), (2.8), (2.9), (2.10) and (2.11), the work (2.1) of this cycle can be determined as:

$\mathrm{W}=\frac{\mathrm{p}_{1} \cdot \mathrm{V}_{1}}{\gamma-1}(\tau-1) \cdot\left(\varepsilon^{\gamma-1}-1\right)-\mathrm{V}_{1} \cdot\left(\mathrm{p}_{0}-\mathrm{p}_{1}\right) \frac{\varepsilon}{\varepsilon-1}=$

$=\mathrm{p}_{1} \cdot \mathrm{V}_{1} \cdot \frac{\mathrm{B}}{\varepsilon^{\gamma-1}}\left(\varepsilon^{\gamma-1}-1\right)-\mathrm{V}_{1} \cdot\left(\mathrm{p}_{0}-\mathrm{p}_{1}\right) \frac{\varepsilon}{\varepsilon-1}$

The efficiency is calculated as:

$\eta_{\mathrm{O}}=\frac{\mathrm{W}}{\mathrm{Q}_{\mathrm{H}}}=$

$$
=\frac{\mathrm{p}_{1} \cdot \mathrm{V}_{1} \cdot \frac{\mathrm{B}}{\varepsilon^{\gamma-1}}\left(\varepsilon^{\gamma-1}-1\right)-\mathrm{p}_{1} \cdot \mathrm{V}_{1} \cdot(\beta-1) \frac{\varepsilon}{\varepsilon-1}}{\frac{\mathrm{m}}{1+\mathrm{A} / \mathrm{F}} \cdot \mathrm{Q}_{\mathrm{LHV}}}
$$

where: $\beta=\frac{p_{0}}{p_{1}}$ is the ratio between the atmospheric pressure and the intake pressure.

Efficiency may also be written as:

$\eta_{\mathrm{o}}=1-\frac{1}{\varepsilon^{\gamma-1}}-\frac{(\beta-1) \cdot(\varepsilon-1) \cdot \varepsilon^{\gamma-2}}{\beta \cdot \mathrm{B} \cdot\left(\varepsilon^{\gamma-1}-1\right)}$

Knowing that the maximum work produced by the Otto cycle is for the non throttled operation (WOT):

$\mathrm{W}_{\max }=\mathrm{W}$ when $\mathrm{p}_{1}=\mathrm{p}_{0}$ or $\mathrm{b}=1$

We get:

$$
\begin{aligned}
& \frac{\mathrm{W}}{\mathrm{W}_{\max }}= \\
& =\frac{\mathrm{p}_{1} \cdot \mathrm{V}_{1} \cdot \frac{\mathrm{B}}{\varepsilon^{\gamma-1}} \cdot\left(\varepsilon^{\gamma-1}-1\right)-\mathrm{p}_{1} \cdot \mathrm{V}_{1} \cdot(\beta-1) \cdot \frac{\varepsilon-1}{\varepsilon}}{\mathrm{p}_{0} \cdot \mathrm{V}_{1} \cdot \frac{\mathrm{B}}{\varepsilon^{\gamma-1}} \cdot\left(\varepsilon^{\gamma-1}-1\right)}
\end{aligned}
$$

We can present an equation that gives the load for the Otto cycle at part load:

$$
\frac{\mathrm{W}}{\mathrm{W}_{\max }}=\frac{1}{\beta}-\frac{(\beta-1) \cdot(\varepsilon-1) \cdot \varepsilon^{\gamma-2}}{\beta \cdot \mathrm{B} \cdot\left(\varepsilon^{\gamma-1}-1\right)}
$$

The values of efficiency of this cycle are plotted against $\beta$ and against load on Figure 3 and Figure 4, respectively for an engine with $\varepsilon=12$.

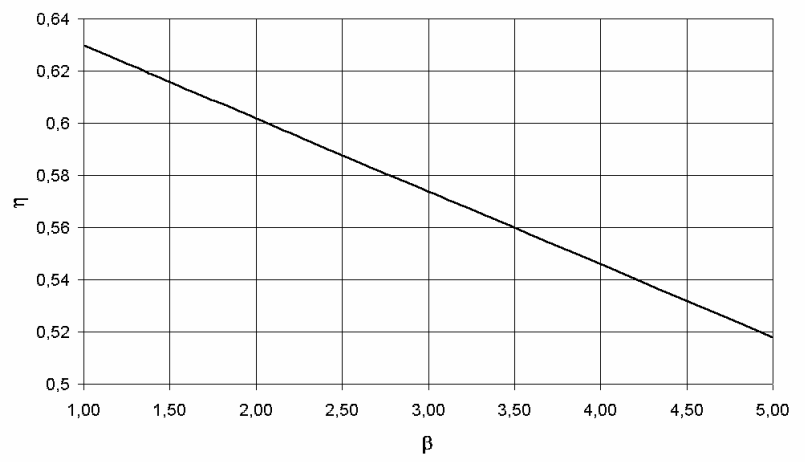

Figure 3 - Thermal efficiency of Otto cycle at part load as a function of pressure ratio.

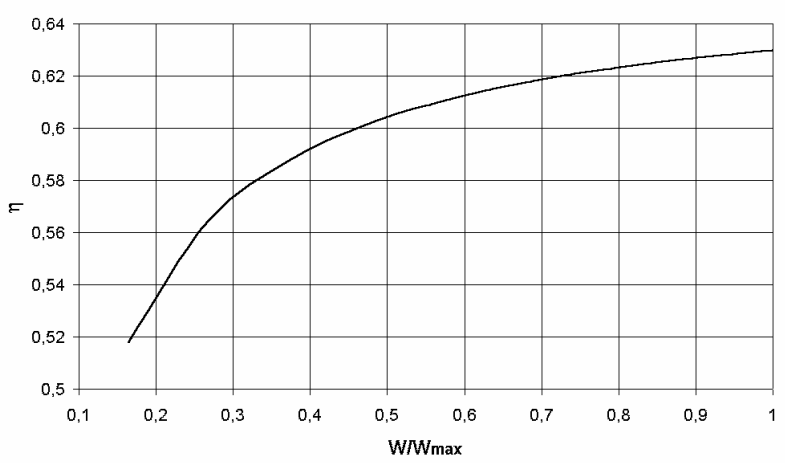

Figure 4 - Thermal efficiency of Otto cycle at part load as a function of load.

\section{OTTO CYCLE WITH DIRECT INJECTION (STRATIFIED CHARGE) AT PART LOAD}

In the previous cycle an amount of work was spent in pumping the mixture so that the intake quantity would be lower than the cylinder capacity at atmospheric conditions. In order to eliminate this work, the direct injection system can be used together with the concept of charge stratification. In this case the quantity of intake air will remain the same (the cylinder volume) but the 
amount of injected fuel will be lowered with the required load, thus using lean mixtures (or using stoichiometric mixture and a large value for EGR). As a consequence, the pressure and temperature at the end of combustion will also be lower. The difference induced by this change in the cycle work can be seen in the $p-V$ diagram (Figure 5 ), as a lower dashed line between points 3' (end of combustion) and 4' (end of expansion).

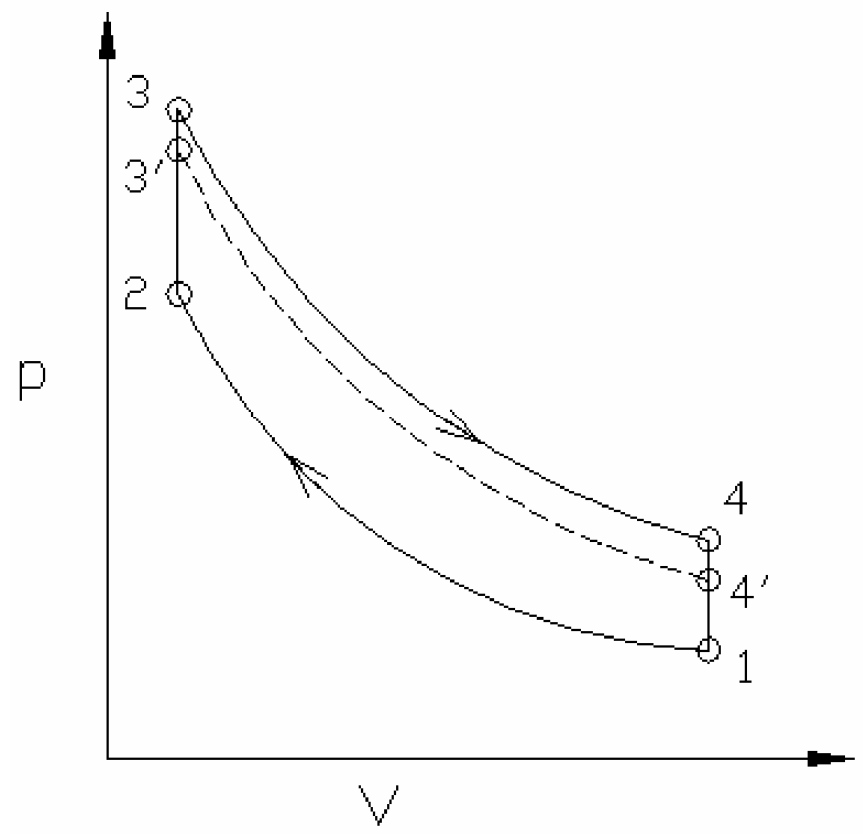

Figure 5 - $p-V$ diagram for the Otto cycle with direct injection.

The efficiency of this cycle can be written as:

$\eta_{\mathrm{OD}}=1-\frac{\frac{\mathrm{T}_{4^{\prime}}}{\mathrm{T}_{2}}-\frac{\mathrm{T}_{1}}{\mathrm{~T}_{2}}}{\frac{\mathrm{T}_{3^{\prime}}}{\mathrm{T}_{2}}-1}$

Considering:

$\frac{\mathrm{T}_{1}}{\mathrm{~T}_{2}}=\frac{1}{\varepsilon^{\gamma-1}}$

$\frac{\mathrm{T}_{3^{\prime}}}{\mathrm{T}_{2}}=1+\frac{(\gamma-1) \cdot \mathrm{Q}_{\mathrm{LHV}}}{\mathrm{R} \cdot \mathrm{T}_{1} \cdot \varepsilon^{\gamma-1}} \cdot \frac{1}{1+\frac{(\mathrm{A} / \mathrm{F})_{\mathrm{S}}}{\Phi}}=$

$=1+\frac{(\gamma-1) \cdot \mathrm{C}}{\varepsilon^{\gamma-1}} \cdot \frac{1}{1+\frac{(\mathrm{A} / \mathrm{F})_{\mathrm{S}}}{\Phi}}$ where $: C=\frac{Q_{L H V}}{R \cdot T_{1}}$ is a constant.

$\Phi$ is the fuel/air equivalent ratio and defined as the relation of the stoichiometric mixture and the effective intake mixture:

$\Phi=\frac{(\mathrm{A} / \mathrm{F})_{\mathrm{s}}}{\mathrm{A} / \mathrm{F}}=\frac{\mathrm{F} / \mathrm{A}}{(\mathrm{F} / \mathrm{A})_{\mathrm{S}}}$

This $\Phi$ represents the load. In fact, when the mixture is stoichimetric, $\Phi$ will assume the value of 1 and less of 1 for lean mixtures.

$\frac{T_{4^{\prime}}}{T_{2}}=\frac{T_{4^{\prime}}}{T_{3^{\prime}}} \cdot \frac{T_{3^{\prime}}}{T_{2}}$

$\frac{\mathrm{T}_{4^{\prime}}}{\mathrm{T}_{3^{\prime}}}=\left(\frac{\mathrm{V}_{3^{\prime}}}{\mathrm{V}_{4^{\prime}}}\right)^{\gamma-1}=\left(\frac{1}{\varepsilon}\right)^{\gamma-1}$

Comes then:

$\frac{\mathrm{T}_{4}}{\mathrm{~T}_{2}}=\frac{1}{\varepsilon^{\gamma-1}} \cdot\left[1+\frac{(\gamma-1) \cdot \mathrm{C}}{\varepsilon^{\gamma-1}} \cdot \frac{1}{1+\frac{(\mathrm{A} / \mathrm{F})_{\mathrm{S}}}{\Phi}}\right]$

It comes then that the efficiency of this cycle will be:

$\eta_{\mathrm{OD}}=1-\frac{\frac{1}{\varepsilon^{\gamma-1}} \cdot\left[1+\frac{(\gamma-1) \cdot \mathrm{C}}{\varepsilon^{\gamma-1}} \cdot \frac{1}{\left.1+\frac{(\mathrm{A} / \mathrm{F})_{\mathrm{S}}}{\Phi}\right]}\right]-\frac{1}{\varepsilon^{\gamma-1}}}{\frac{(\gamma-1) \cdot \mathrm{C}}{\varepsilon^{\gamma-1}} \cdot \frac{1}{1+\frac{(\mathrm{A} / \mathrm{F})_{\mathrm{S}}}{\Phi}}}=$

$=1-\frac{1}{\varepsilon^{\gamma-1}}$

As can be seen from (3.8), the efficiency of this cycle is not dependent on the fuel/air equivalent ratio. This is as expected, as the Otto cycle is not a function of load, only compression ratio. 


\section{MILLER CYCLE}

Following the cycle presented in Figure 1, compression occurs from 1 to 2 , and the combustion until 3 . Expansion is performed from 3 to 4 that correspond to the total length of the piston stroke from TDC to BDC. In 4 the exhaust valve is opened starting the exhaust. At TDC the exhaust valve is closed and the intake valve is opened, and it is kept opened during the descent of the piston from TDC to BDC and for part of the upward stoke, being closed only at point 1 . In the theoretical study it is considered a closed cycle (constant mass, like Otto or Diesel cycles) that loses heat in processes 4-5 and 5-1 and the processes 1-0 and 0-1 are not considered as they are reversed.

To the thermal efficiency study of the Miller cycle, it will be necessary to deduce expressions to calculate temperatures in the different points of the cycle. These points and processes are those represented in the diagram of Figure 1.

Values for point 1 are considered the standard atmospheric pressure and temperature: $p_{1}, T_{1}$.

Point 2 corresponds to the end of compression (assumed as isentropic) initiated at 1 , so the calculation of $T_{2}$ is made applying the conditions of isentropic transformations for ideal gases:

$\mathrm{T}_{2}=\mathrm{T}_{1}\left(\frac{\mathrm{V}_{1}}{\mathrm{~V}_{2}}\right)^{\gamma-1}=\mathrm{T}_{1} \varepsilon_{\mathrm{tr}}^{\gamma-1}=\mathrm{T}_{1}\left(\frac{\varepsilon_{\mathrm{g}}}{\sigma}\right)^{\gamma-1}$

The evolution from 2 to 3 corresponds to the internal combustion of the air-fuel mixture. The process is isochoric and can be described as the pressure and temperature increase, as a result of the combustion of the fuel presented in the cylinder. The generated heat during this reaction may be expressed as:

$\mathrm{m} \cdot \mathrm{c}_{\mathrm{v}} \cdot\left(\mathrm{T}_{3}-\mathrm{T}_{2}\right)=\mathrm{m}_{\mathrm{f}} \cdot \mathrm{Q}_{\mathrm{LHV}}$

Where:

$m$ - mass of the mixture inside the cylinder

$\mathrm{C}_{\mathrm{v}}$ - specific heat at constant volume

$m_{f}-$ mass of fuel contained in the mixture

$Q_{\mathrm{LHV}}$ - lower heating value of the fuel

From (4.2) comes:

$$
\begin{gathered}
\frac{\mathrm{T}_{3}}{\mathrm{~T}_{2}}=1+\frac{\mathrm{m}_{\mathrm{f}} \cdot \mathrm{Q}_{\mathrm{L}}}{\mathrm{m} \cdot \mathrm{c}_{\mathrm{v}} \cdot \mathrm{T}_{1} \cdot \varepsilon^{\gamma-1}}= \\
=1+\frac{\frac{(\gamma-1) \cdot \frac{\mathrm{m}}{\mathrm{F}}+1}{\varepsilon_{\mathrm{tr}}^{\gamma-1} \cdot \mathrm{p}_{1} \cdot \Delta \mathrm{V}}}{\mathrm{Q}_{\mathrm{L}}}
\end{gathered}
$$

Considering:

$$
\mathrm{B}=\frac{\mathrm{m} \cdot \mathrm{Q}_{\mathrm{LHV}}}{\mathrm{p}_{1} \cdot \Delta \mathrm{V} \cdot(1+\mathrm{A} / \mathrm{F})}
$$

This, and substituting $T_{2}$ by (4.1) will allow (4.3) to be written as:

$$
\frac{\mathrm{T}_{3}}{\mathrm{~T}_{1}}=\left(\frac{\varepsilon_{\mathrm{g}}}{\sigma}\right)^{\gamma-1}+(\gamma-1) \cdot \mathrm{B}
$$

From point 3 to 4 it is made the expansion of the gases resulting from the combustion. This expansion is made during the entire piston stroke and it is considered as an isentropic transformation. Applying the perfect gas law to an isentropic transformation that comes:

$\frac{\mathrm{T}_{4}}{\mathrm{~T}_{3}}=\left(\frac{1}{\varepsilon_{\mathrm{g}}}\right)^{\gamma-1}$

Substituting $T_{3}$ by (4.5) comes:

$\frac{\mathrm{T}_{4}}{\mathrm{~T}_{1}}=\frac{1}{\sigma^{\gamma-1}}+\frac{(\gamma-1) \cdot \mathrm{B}}{\varepsilon_{\mathrm{g}}^{\gamma-1}}$

Or

$\frac{\mathrm{T}_{4}}{\mathrm{~T}_{1}}=\frac{1}{\sigma^{\gamma-1}}+\frac{(\gamma-1) \cdot \mathrm{B}}{\sigma^{\gamma-1} \varepsilon_{\mathrm{tr}}^{\gamma-1}}$

At point 5 it is considered that the pressure is equal to the pressure at point 1 , which allows the deduction using the perfect gas law:

$$
\frac{\mathrm{T}_{5}}{\mathrm{~T}_{1}}=\sigma
$$

$\mathrm{T}_{0}$ calculate the thermal efficiency and using the second law corollaries, the expression used to calculate the thermal efficiency of the Miller cycle is ( $G$ refers to geometric compression ratio): 


$$
\begin{aligned}
& \eta_{M G}=1-\frac{Q_{4-5}+Q_{5-1}}{Q_{2-3}}= \\
& =1-\frac{T_{4}-T_{5}+\gamma\left(T_{5}-T_{1}\right)}{T_{3}-T_{2}}
\end{aligned}
$$

Substituting $T_{2}, T_{3}, T_{4}$ e $T_{5}$ by (4.1), (4.5), (4.8) e (4.9) respectively, (4.10) can be written as:

$\eta_{\mathrm{MG}}=1-\frac{1}{\varepsilon_{\mathrm{g}}^{\gamma-1}}-\frac{\sigma^{\gamma}(\gamma-1)-\gamma \cdot \sigma^{\gamma-1}+1}{(\gamma-1) \cdot \sigma^{\gamma-1} \cdot \mathrm{B}}$

Using this expression it is possible to represent graphically the thermal efficiency of Miller cycle as a function of $\sigma$, for several geometric compression ratios $\varepsilon_{g}$. This diagram is shown in Figure 6.

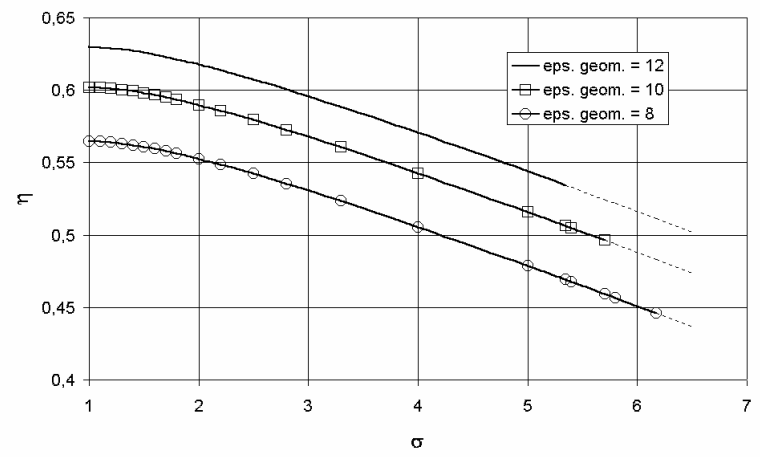

Figure 6 - Thermal efficiency as a function of $\sigma$ for different geometric compression ratios.

In this situation engine efficiency values are calculated keeping the geometric compression ratio constant at typical values used in spark ignition engines. This implies that when raising the value of $\sigma$, the pressure at the end of the compression decreases once the trapped compression ratio, (which is the real compression ratio of the mixture contained in the cylinder), is reduced for the same geometric compression ratio. In this figure it is possible to observe that the maximum efficiency is obtained with $\sigma=1$, that is the Otto cycle. Simultaneously it is possible to observe that when raising the geometric compression ratio, efficiency also raises. This is due to the corresponding raise of pressure (and temperature) obtained at the end of the compression stroke. Dashed lines represent the cases when the pressure at the end of the expansion stroke is lower than the atmospheric pressure.

Considering now that instead of keeping the geometric compression ratio constant, we keep the trapped compression ratio and the engine displacement constant, so the expression (4.11) may be written using expression (1.4) (substituting $\varepsilon_{\mathrm{g}}$ by $\varepsilon_{\mathrm{tr}} \sigma$ ):

$$
\eta_{\mathrm{MT}}=1-\frac{1}{\varepsilon_{\mathrm{tr}}{ }^{\gamma-1} \cdot \sigma^{\gamma-1}}-\frac{\sigma^{\gamma}(\gamma-1)-\gamma \cdot \sigma^{\gamma-1}+1}{(\gamma-1) \cdot \sigma^{\gamma-1} \cdot \mathrm{B}}
$$

A graphic representation of this expression is shown in Figure 7.

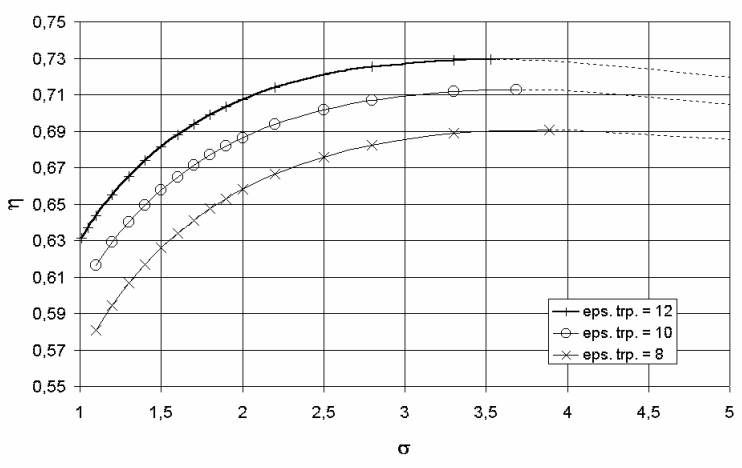

Figure 7 - Thermal efficiency as a function of $\sigma$ for different trapped compression ratios.

In Figure 7 is clear that the efficiency increases when comparing the Miller cycle with the Otto cycle $(\sigma=1)$. Once the engine displacement is kept constant, the increase of $\sigma$ implies a reduction of the combustion chamber volume (point 2 of the $\mathrm{p}-\mathrm{V}$ diagram in Figure 1)

With the objective of using all the Miller cycle potential, it shall be necessary to know the maximum value of $\sigma$ which occurs when, at the end of expansion, the pressure equals the admission pressure. At such point the engine efficiency is maximum and corresponds to the Atkinson cycle, in which the expansion is extended to its maximum. In Figure 7 the transition from continuous to dashed lines represents this point of maximum efficiency.

So it is necessary to determine the volume where the pressure at 4 equals the pressure at 1 . Using the isentropic expressions for ideal gas:

$\mathrm{p}_{4}=\mathrm{p}_{3}\left(\frac{\mathrm{V}_{3}}{\mathrm{~V}_{4}}\right)^{\gamma}=\mathrm{p}_{3}\left(\frac{1}{\varepsilon_{\mathrm{g}}}\right)^{\gamma}$

Using expressions (4.5) and (1.2) successively comes:

$\mathrm{p}_{4}=\mathrm{p}_{3}\left(\frac{1}{\varepsilon_{\mathrm{g}}}\right)^{\gamma}=\mathrm{p}_{2}\left[1+\frac{(\gamma-1) \cdot \mathrm{B}}{\varepsilon_{\mathrm{tr}}^{\gamma-1}}\right] \cdot\left(\frac{1}{\varepsilon_{\mathrm{g}}}\right)^{\gamma}$ 


$$
\begin{aligned}
& \mathrm{p}_{4}=\mathrm{p}_{1}\left(\frac{1}{\sigma}\right)^{\gamma} \cdot\left[1+\frac{(\gamma-1) \cdot \mathrm{B} \cdot \sigma^{\gamma-1}}{\varepsilon_{\mathrm{g}}^{\gamma-1}}\right]= \\
& =\mathrm{p}_{1} \cdot \frac{1}{\sigma^{\gamma}}\left[1+\frac{(\gamma-1) \cdot \mathrm{B}}{\varepsilon_{\mathrm{tr}}^{\gamma-1}}\right]
\end{aligned}
$$

In Figure 8 is represented (4.15) with $p_{4} / p_{1}$ function of $\sigma$.

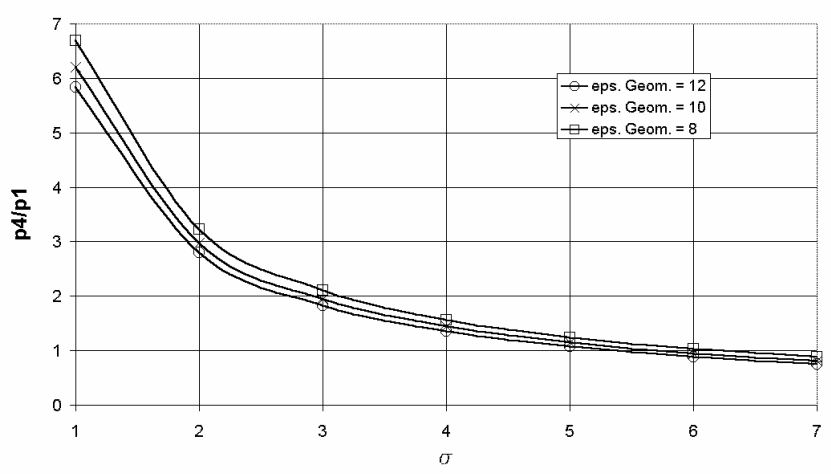

Figure 8 - Relation between $p_{4} / p_{1}$ and $\sigma$ for different $\varepsilon_{g}$.

From Figure 8 it is possible to conclude that $\sigma$ may be raised until a value close to 6 , in which pressure value at the end of expansion is closer to the pressure at 1 .

Also from Figure 4 it is possible to conclude that the higher the $\varepsilon_{g}$ the lower the ratio between $p_{4}$ and $p_{1}$, for the same values of $\sigma$.

To determine the value of optimal $\sigma$, it is necessary to differentiate expression (4.11) in relation to $\sigma$, and equalize it to 0 , obtaining the values of the optimal value of $\sigma$ function of $\varepsilon_{t r}$.

$\frac{\mathrm{d} \eta}{\mathrm{d} \sigma}=0 \Rightarrow \sigma_{\mathrm{opt}}=\left[1+\frac{(\gamma-1) \cdot \mathrm{B}}{\varepsilon_{\mathrm{tr}}^{\gamma-1}}\right]^{\frac{1}{\gamma}}$

Knowing that $p_{4}$ should be higher than $p_{1}$ (limit situation of the Miller cycle) it comes:

$\frac{1}{\sigma^{\gamma}}\left[1+\frac{(\gamma-1) \cdot \mathrm{B}}{\varepsilon_{\mathrm{tr}}{ }^{\gamma-1}}\right] \geq 1 \Leftrightarrow \sigma \leq\left[1+\frac{(\gamma-1) \cdot \mathrm{B}}{\varepsilon_{\mathrm{tr}}{ }^{\gamma-1}}\right]^{\frac{1}{\gamma}}$

In Figure 9 is represented the relation between the value of optimal $\sigma$ and the value of trapped compression ratio.

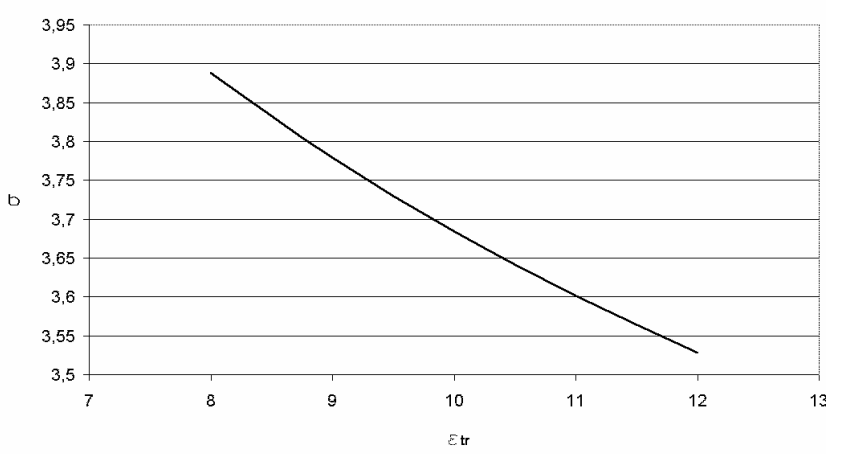

Figure 9 - Values for optimal $\sigma$ for different values of trapped compression ratio.

It is possible to determine the maximum Miller cycle efficiency for different values of trapped compression ratio. The evolution of these values is represented in Figure 10. The Miller cycle with full expansion to atmospheric pressure it is also known as the Atkinson cycle.

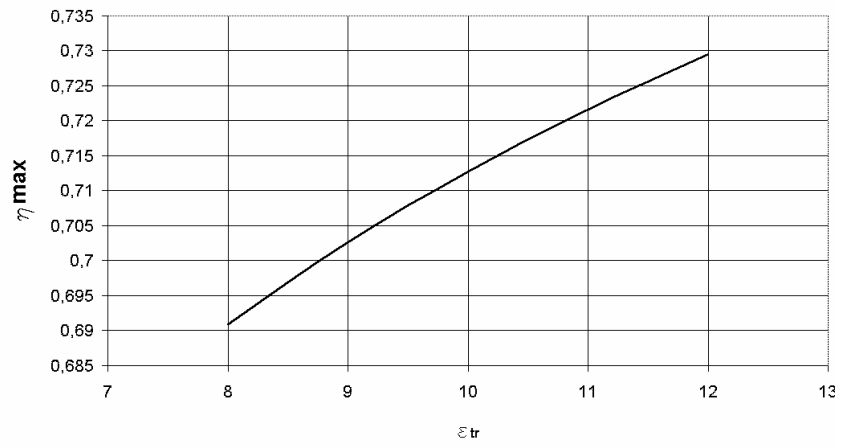

Figure 10 - Maximum efficiency vs. trapped compression ratio.

\section{DIESEL CYCLE AT PART LOAD}

In the Diesel cycle the load is controlled by the amount of fuel supplied during the injection. The amount of intake air is the same as there is no restriction on the intake. So, the change in the cycle configuration due to a lower load (lean mixture) will be the reduction of the heat supplied during the isobaric heating. In the $\mathrm{p}-\mathrm{V}$ diagram (Figure 11) it can be seen the difference between the full load cycle and the part load cycle, plotted with a dashed line. 


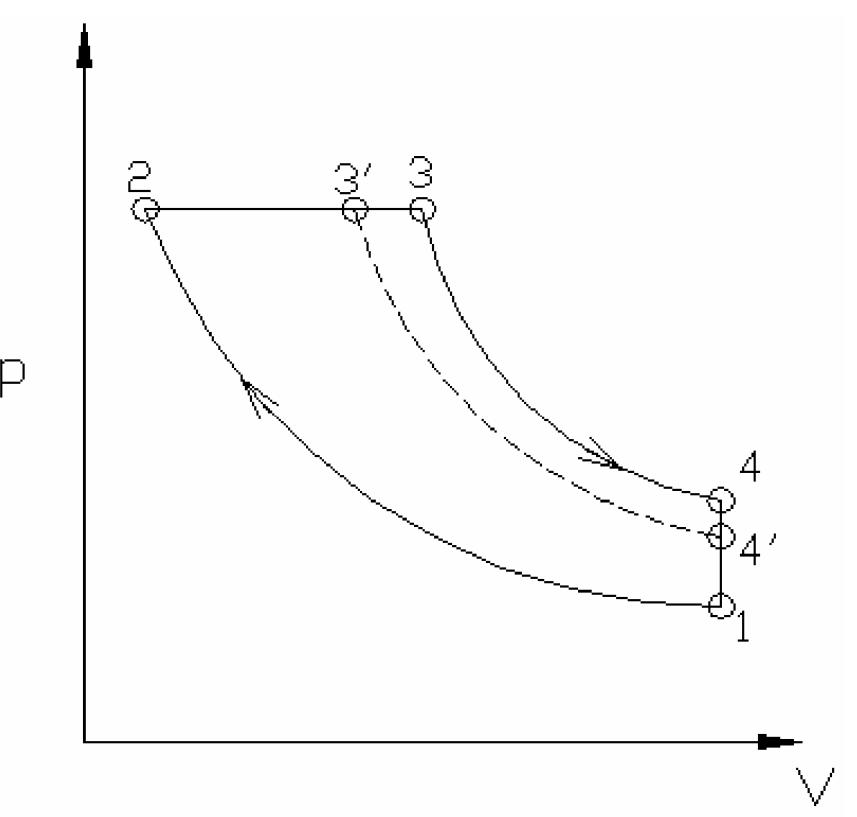

Figure $11-p-V$ diagram of the Diesel cycle.

The efficiency of this cycle can be calculated by:

$$
\eta_{D}=1-\frac{T_{4^{\prime}}-T_{1}}{\gamma \cdot\left(T_{3^{\prime}}-T_{2}\right)}=1-\frac{\frac{T_{4^{\prime}}}{T_{2}}-\frac{T_{1}}{T_{2}}}{\gamma \cdot\left(\frac{T_{3^{\prime}}}{T_{2}}-1\right)}
$$

Dividing the cycle into its various processes:

Isentropic compression process during the entire compression stroke from 1 to 2 .

$$
\mathrm{p}_{2}=\mathrm{p}_{1} \cdot \varepsilon^{\gamma} \quad \mathrm{T}_{2}=\mathrm{T}_{1} \cdot \varepsilon^{\gamma-1} \quad \mathrm{~V}_{2}=\frac{\mathrm{V}_{1}}{\varepsilon}
$$

Isobaric heating from 2 to 3 during the combustion process.

$\mathrm{Q}_{2-3}=\mathrm{m} \cdot \mathrm{c}_{\mathrm{p}} \cdot\left(\mathrm{T}_{3^{\prime}}-\mathrm{T}_{2}\right)=\mathrm{m}_{\mathrm{f}} \cdot \mathrm{Q}_{\mathrm{LHV}}$

$$
\begin{aligned}
& \frac{\mathrm{T}_{3^{\prime}}}{\mathrm{T}_{2}}=1+\frac{\mathrm{m}_{\mathrm{f}} \cdot \mathrm{Q}_{\mathrm{LHV}}}{\mathrm{m} \cdot \mathrm{c}_{\mathrm{p}} \cdot \mathrm{T}_{2}}= \\
& =1+\frac{(\gamma-1) \cdot \mathrm{Q}_{\mathrm{LHV}}}{\gamma \cdot \mathrm{R} \cdot \mathrm{T}_{1} \cdot \varepsilon^{\gamma-1}} \cdot \frac{1}{1+\frac{(\mathrm{A} / \mathrm{F})_{\mathrm{S}}}{\Phi}}=\mathrm{A}(\Phi)
\end{aligned}
$$

Isentropic expansion from 3 to 4 .

$$
\begin{aligned}
& \mathrm{T}_{3^{\prime}} \cdot \mathrm{V}_{3^{\prime}}{ }^{\gamma-1}=\mathrm{T}_{4^{\prime}} \cdot \mathrm{V}_{4^{\prime}}{ }^{\gamma-1} \rightarrow \\
& \rightarrow \mathrm{T}_{4^{\prime}}=\mathrm{T}_{3^{\prime}} \cdot\left(\frac{\mathrm{V}_{3^{\prime}}}{\mathrm{V}_{4^{\prime}}}\right)^{\gamma-1} \\
& \frac{\mathrm{T}_{4^{\prime}}}{\mathrm{T}_{2}}=\frac{\mathrm{T}_{3^{\prime}}}{\mathrm{T}_{2}} \cdot\left(\frac{\mathrm{V}_{3^{\prime}}}{\mathrm{V}_{4^{\prime}}}\right)^{\gamma-1}=\mathrm{A}(\Phi) \cdot\left(\frac{\mathrm{V}_{3^{\prime}}}{\mathrm{V}_{4^{\prime}}}\right)^{\gamma-1}
\end{aligned}
$$

With (5.2) and (5.4):

$$
\frac{\mathrm{T}_{3^{\prime}}}{\mathrm{T}_{2}}=\frac{\mathrm{V}_{3^{\prime}}}{\mathrm{V}_{2}} \quad \mathrm{~V}_{3^{\prime}}=\frac{\mathrm{V}_{1}}{\varepsilon} \cdot \mathrm{A}(\Phi)
$$

Comes:

$$
\frac{\mathrm{T}_{4^{\prime}}}{\mathrm{T}_{2}}=[\mathrm{A}(\Phi)]^{\gamma} \cdot\left(\frac{1}{\varepsilon}\right)^{\gamma-1}
$$

The expression (5.1) for the efficiency of this cycle can be written as:

$$
\begin{aligned}
& \eta_{\mathrm{D}}=1-\frac{[\mathrm{A}(\Phi)]^{\gamma} \cdot\left(\frac{1}{\varepsilon}\right)^{\gamma-1}-\left(\frac{1}{\varepsilon}\right)^{\gamma-1}}{\gamma \cdot[\mathrm{A}(\Phi)-1]}= \\
& =1-\left(\frac{1}{\varepsilon}\right)^{\gamma-1} \cdot \frac{[\mathrm{A}(\Phi)]^{\gamma}-1}{\gamma \cdot[\mathrm{A}(\Phi)-1]}
\end{aligned}
$$

In Figure 12 are plotted the values for the efficiency of this cycle, using this expression.

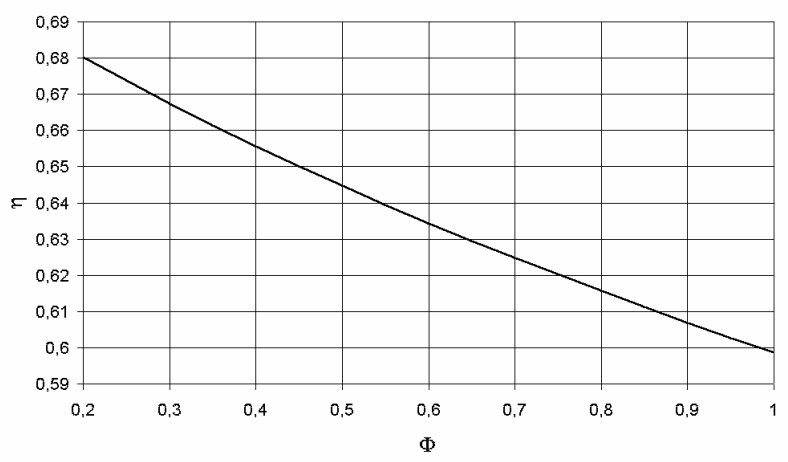

Figure 12 - Thermal efficiency as a function $\Phi$ for the Diesel cycle.

As it can be seen the efficiency increases as the mixture becomes leaner. This is due to the fact that when using 
leaner mixtures, the heat supplied during the combustion is lower, which will cause the pressure at final of combustion to be also lower, therefore with less losses when the exhaust valve opens. In the extreme case, (no heat supplied) the expansion leads to the initial point (but no work is done, also).

\section{DUAL CYCLE AT PART LOAD}

In the dual cycle the heat is supplied at the TDC, at constant volume (isochoric) and during the descent of the piston, at constant pressure (isobaric). In this cycle it will be considered that a reduction of the load (using lean mixtures) will cause only the reduction of the heat supplied during the descent of the piston (isobaric). The heat supplied at constant volume in TDC is considered constant and independent of the load. This heat can be considered as the fuel supplied during the pre-injections used in the modern Diesel engines, (which is roughly constant with load) and at the first part of the main injection. In this paper the fuel supplied at constant volume is considered to be $1 / 10$ of the stoichiometric fuelling.

In the $\mathrm{p}-\mathrm{V}$ diagram of the dual cycle (Figure 13) it is possible to see, (dashed line) the expansion stroke of the dual cycle at part load, under the line for the full load expansion.

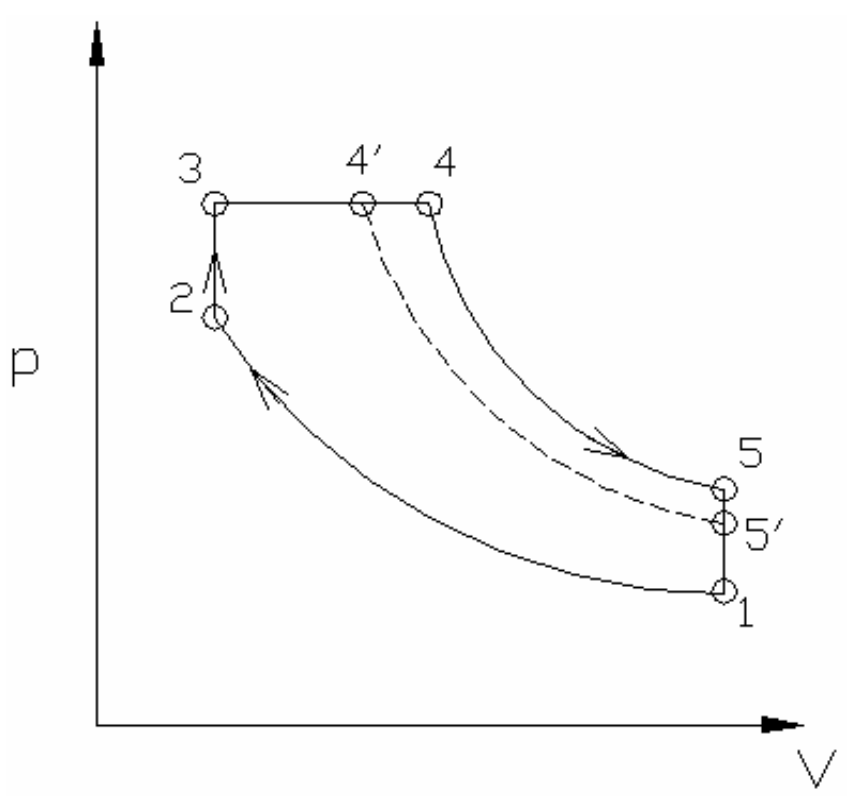

Figure $13-p-V$ diagram of the dual cycle.

For the dual cycle, the thermal efficiency may be determined by:

$$
\begin{gathered}
\eta_{d}=1-\frac{T_{5^{\prime}}-T_{1}}{T_{3}-T_{2}+\gamma \cdot\left(T_{4^{\prime}}-T_{3}\right)}= \\
=1-\frac{\frac{T_{5^{\prime}}}{T_{2}}-\frac{T_{1}}{T_{2}}}{\frac{T_{3}}{T_{2}}-1+\gamma \cdot\left(\frac{T_{4^{\prime}}}{T_{2}}-\frac{T_{3}}{T_{2}}\right)}
\end{gathered}
$$

The heat supplied during the combustion, at constant volume and at constant pressure may be represented as:

$$
\begin{aligned}
& \mathrm{Q}_{2-3}+\mathrm{Q}_{3-4}= \\
& =\mathrm{m} \cdot \mathrm{c}_{\mathrm{v}} \cdot\left[\left(\mathrm{T}_{3}-\mathrm{T}_{2}\right)+\gamma \cdot\left(\mathrm{T}_{4}-\mathrm{T}_{3}\right)\right]=\mathrm{m}_{\mathrm{f}} \cdot \mathrm{Q}_{\mathrm{LHV}}
\end{aligned}
$$

Comes then:

$$
\begin{aligned}
& \frac{\mathrm{T}_{3}}{\mathrm{~T}_{2}}+\gamma \cdot\left(\frac{\mathrm{T}_{4^{\prime}}}{\mathrm{T}_{2}}-\frac{\mathrm{T}_{3}}{\mathrm{~T}_{2}}\right)= \\
& =1+\frac{(\gamma-1) \cdot \mathrm{Q}_{\mathrm{LHV}}}{\mathrm{R} \cdot \mathrm{T}_{1} \cdot \varepsilon^{\gamma-1}} \cdot \frac{1}{1+\frac{\mathrm{A} / \mathrm{F})_{\mathrm{S}}}{\Phi}}=1+\mathrm{B}(\Phi, \Psi)
\end{aligned}
$$

$\frac{\mathrm{T}_{4^{\prime}}}{\mathrm{T}_{2}}=\frac{1+\mathrm{B}(\Phi, \Psi)+\frac{\mathrm{T}_{3}}{\mathrm{~T}_{2}} \cdot(\gamma-1)}{\gamma}$

Where:

$$
\mathrm{B}(\Phi, \Psi)=1+\frac{(\gamma-1) \cdot \mathrm{Q}_{\mathrm{LHV}}}{\mathrm{R} \cdot \mathrm{T}_{1} \cdot \varepsilon^{\gamma-1}} \cdot \frac{1}{1+\frac{(\mathrm{A} / \mathrm{F})_{\mathrm{S}}}{\Phi}}
$$

Considering:

$\Phi=\frac{\mathrm{Q}_{\mathrm{T}}^{\prime}}{\mathrm{Q}_{\mathrm{T}}} \quad \Psi=\frac{\mathrm{Q}_{\mathrm{V}}}{\mathrm{Q}_{\mathrm{T}}} \quad \Psi^{\prime}=\frac{\mathrm{Q}_{\mathrm{V}}}{\mathrm{Q}_{\mathrm{T}}^{\prime}}$

It results: $\Psi^{\prime}=\frac{\Psi}{\Phi}$

In fact $\Phi$ can be considered the load factor. In equation (3.4) $\Phi$ is defined as the fuel/air equivalent ratio, representing the relation between the effective intake fuel and the stoichiometric fuel quantity. The same relation can be obtained (considering that the heat supplied at constant volume is always constant) when the relation is established between the heat supplied at constant pressure for a determined amount of fuel and the heat supplied at constant pressure when considering a stoichiometric mixture. 
The heat supplied during the constant volume combustion is represented as:

$\mathrm{Q}_{2-3}=\mathrm{m} \cdot \mathrm{c}_{\mathrm{v}} \cdot\left(\mathrm{T}_{3}-\mathrm{T}_{2}\right)=\Psi \cdot \mathrm{m}_{\mathrm{f}} \cdot \mathrm{Q}_{\mathrm{LHV}}$

with $\Psi<1$

Comes then:

$\frac{\mathrm{T}_{3}}{\mathrm{~T}_{2}}=1+\frac{(\gamma-1) \cdot \Psi \cdot \mathrm{Q}_{\mathrm{LHV}}}{\mathrm{R} \cdot \mathrm{T}_{1} \cdot \varepsilon^{\gamma-1}} \cdot \frac{1}{1+(\mathrm{A} / \mathrm{F})_{\mathrm{S}}}=\mathrm{A}(\Psi)$

$\mathrm{T}_{3}=\mathrm{A}(\Psi) \cdot \mathrm{T}_{2}=\mathrm{A}(\Psi) \cdot \mathrm{T}_{1} \cdot \varepsilon^{\gamma-1}$

(6.4) can be written as:

$\frac{\mathrm{T}_{4^{\prime}}}{\mathrm{T}_{2}}=\frac{1+\mathrm{B}(\Phi, \Psi)+(\gamma-1) \cdot\left[1+\frac{(\gamma-1) \cdot \Psi \cdot \mathrm{Q}_{\mathrm{LHV}}}{\mathrm{R} \cdot \mathrm{T}_{1} \cdot \varepsilon^{\gamma-1}} \cdot \frac{1}{1+(\mathrm{A} / \mathrm{F})_{\mathrm{S}}}\right]}{\gamma}=$$$
=\frac{1+\mathrm{B}(\Phi, \Psi)+(\gamma-1) \cdot \mathrm{A}(\Psi)}{\gamma}
$$

The expansion, considered as an isentropic process can be represented as:

$\frac{\mathrm{T}_{5^{\prime}}}{\mathrm{T}_{4^{\prime}}}=\left(\frac{\mathrm{V}_{4^{\prime}}}{\mathrm{V}_{5^{\prime}}}\right)^{\gamma-1}=\left(\frac{\mathrm{V}_{4^{\prime}}}{\mathrm{V}_{1}}\right)^{\gamma-1}$

Considering:

$\mathrm{Q}_{3-4^{\prime}}=\mathrm{m} \cdot \mathrm{c}_{\mathrm{p}} \cdot\left(\mathrm{T}_{4^{\prime}}-\mathrm{T}_{3}\right)=$

$=\left(1-\Psi^{\prime}\right) \cdot \mathrm{m}_{\mathrm{f}} \cdot \mathrm{Q}_{\mathrm{LHV}}$

$\frac{\mathrm{T}_{4^{\prime}}}{\mathrm{T}_{3}}=\mathrm{C}(\Phi, \Psi)=$

$=1+\frac{\left(1-\frac{\Psi}{\Phi}\right) \cdot \mathrm{Q}_{\mathrm{LHV}}}{\frac{\gamma}{\gamma-1} \cdot \mathrm{R} \cdot \mathrm{A}(\Psi) \cdot \mathrm{T}_{1} \cdot \varepsilon^{\gamma-1}} \cdot \frac{1}{1+\frac{(\mathrm{A} / \mathrm{F})_{\mathrm{S}}}{\Phi}}=\mathrm{C}(\Phi, \Psi)$

$\frac{\mathrm{T}_{4^{\prime}}}{\mathrm{T}_{3}}=\frac{\mathrm{V}_{4^{\prime}}}{\frac{\mathrm{V}_{1}}{\varepsilon}}$

(6.10) can be written as :

$$
\frac{\mathrm{T}_{5^{\prime}}}{\mathrm{T}_{4^{\prime}}}=\left[\frac{\mathrm{C}(\Phi, \Psi)}{\varepsilon}\right]^{\gamma-1}
$$

From (6.14) and (6.9):

$$
\begin{aligned}
& \frac{\mathrm{T}_{5^{\prime}}}{\mathrm{T}_{2}}=\frac{\mathrm{T}_{5^{\prime}}}{\mathrm{T}_{4^{\prime}}} \cdot \frac{\mathrm{T}_{4^{\prime}}}{\mathrm{T}_{2}}= \\
& =\left(\frac{1}{\varepsilon}\right)^{\gamma-1} \cdot \mathrm{C}(\Phi, \Psi)^{\gamma-1} \cdot \frac{1+\mathrm{B}(\Phi, \Psi)+(\gamma-1) \cdot \mathrm{A}(\Psi)}{\gamma}
\end{aligned}
$$

From (6.3) (6.9) and (6.15), the efficiency (6.1) can be written as:

$\eta_{\mathrm{d}}=1-\left(\frac{1}{\varepsilon}\right)^{\gamma-1} \cdot \frac{\mathrm{C}(\Phi, \Psi)^{\gamma-1} \cdot \frac{1+\mathrm{B}(\Phi, \Psi)+(\gamma-1) \cdot \mathrm{A}(\Psi)}{\gamma}-1}{\mathrm{~B}(\Phi, \Psi)}$

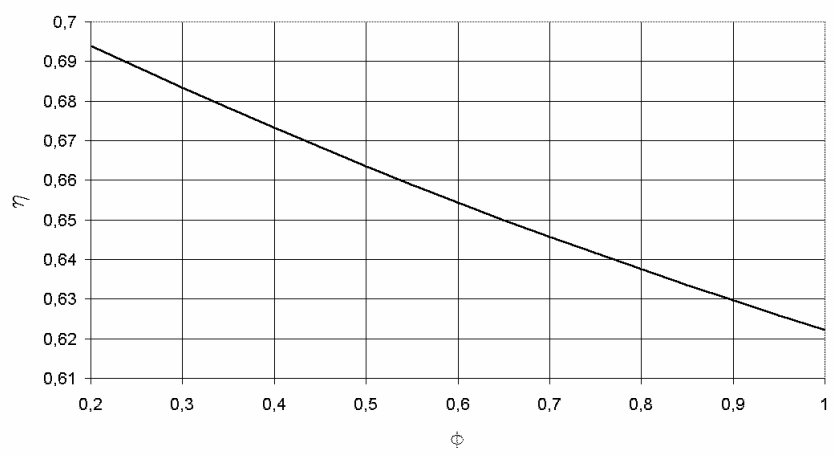

Figure 14 - Thermal efficiency of the dual cycle as a function of $\Phi$ for $\varepsilon=18: 1$.

In Figure 14 we can see the values of the thermal efficiency of the cycle for a compression ratio at 18 . As expected the efficiency decreases with the increase of load (richness of the mixture).

\section{CYCLE COMPARISONS}

The comparison of all the discussed cycles is done as a function of the load of the engine in Figure 15. For the Otto cycle at part load the load is represented by the ratio $\mathrm{W} / \mathrm{W}_{\max }$ as mentioned above (2.16). For the injected Otto cycle, the Diesel cycle and the dual cycle the load is represented by $\Phi$ (the fuel/air equivalent ratio), and in the Miller cycle (with fixed $\varepsilon_{\mathrm{tr}}$ and fixed $\varepsilon_{\mathrm{g}}$ ) the load is represented by the inverse of the expansion ratio $(\sigma=2$ is the same as $1 / 2$ load). It was considered a compression ratio of 12 for the Miller, Otto part load and Otto direct 
injection, 20 for the dual cycle at part load and 22 for the Diesel cycle.

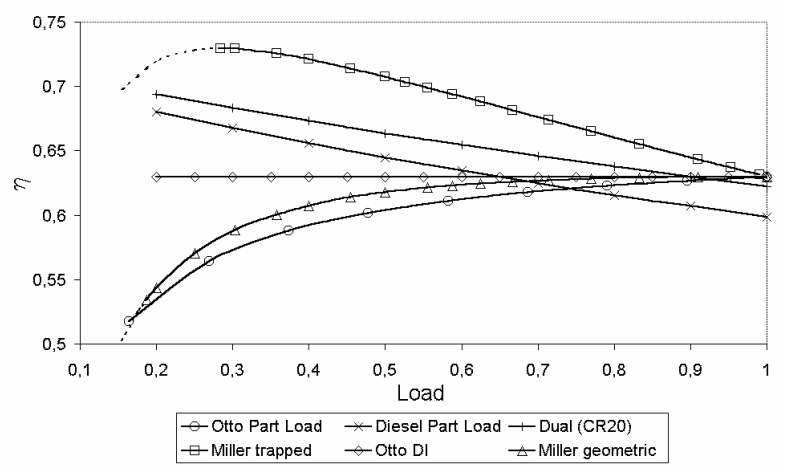

Figure 15 - Comparison of the thermal efficiency of the several cycles at part load.

As it can be seen in the graphic with the several efficiency curves function of the load (Figure 15), two behaviours may be distinguished. The Diesel and dual cycles have an efficiency that increases as the load decreases. On the other hand, the Otto cycle and the Miller (geometric) cycle have an efficiency that rises as the load also rises.

As the load gets closer to 1, Otto part load cycle, Otto direct injection cycle and Miller cycle tend to the same value, $63 \%$, which corresponds to the Otto cycle at full load (WOT). As seen, the Otto direct injection cycle keeps its efficiency independent from the load factor.

Comparing the four spark ignition engines, Miller trapped, Miller geometric, Otto part load and Otto direct injection, it is clear that for engines mainly operated at partial loads the use of the Miller (trapped) cycle is always the best, because the engine is always running near its limiting (by knock) conditions.

In Figure 15 the plotted Dual cycle has a compression ratio of 20 , and this cycle is the one more close to the Miller "trapped". A more detailed comparison was made between these two cycles, plotting the efficiency of the dual cycle for higher compression ratios of 22 and 25 . The values of the efficiency for these cycles are plotted in Figure 16.

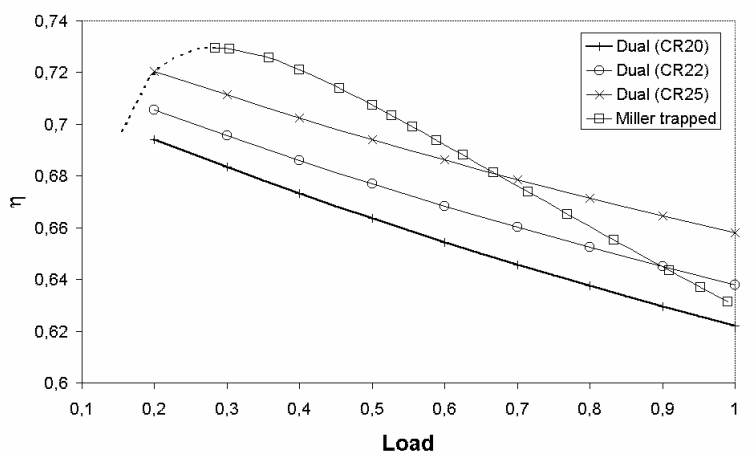

Figure 16 - Comparison of the Miller cycle and the dual cycle thermal efficiencies at different compression ratios.

As it can be seen from Figure 16, the Miller cycle "trapped" still is more efficient than the dual cycle at a compression ratio of 25 , (which can be considered excessive), for a load factor of less than 0.7 .

\section{CALCULATION WITH INDICATED CYCLE}

\section{COMPUTER MODEL}

In order to obtain results to confirm the theoretical efficiency improvement of the Miller cycle, we used a model of the indicated cycle built in Microsoft Excel. This computer program is used for basic thermodynamic computation of the working cycle of a four-stroke reciprocating internal combustion engine (indicated cycle).

The whole working cycle calculation is carried on with a compute step of $\Delta \alpha=1^{\circ}$ crank angle. Each step is carried on a few sequential changes and it is possible to work alternately with medium properties of cylinder charge according to applied fuel and mixture richness.

Assumptions and compute algorithm:

- $\quad$ The state quantities are known from an antecedent step;

- The assessment of the charge properties for temperature $T_{n}$ by using embedded subprogram;

- The volume change of a compute step is considered as combination of an adiabatic and an isochoric change:

- The adiabatic volume change from initial to final volume in a compute step (with constant charge mass) with definition new state quantities at end of the change;

- The isochoric change represents heat-transfer (a heat transfer between cylinder charge and cylinder liner is calculated by Eichelberg or Woschni equations) and combustion heat input (calculation by the Wiebe's characteristic combustion equation) with change of cylinder charge from mixture on 
combustion gases and with calculation of these medium changes in medium properties of cylinder charge.

\section{CALCULATION RESULTS}

Using the software tool described above, four engines were simulated with different geometric characteristics and different working cycles (Table 1).

\begin{tabular}{|c|l|l|}
\hline \multicolumn{2}{|c|}{ Engine cycle } & \multicolumn{1}{c|}{ Description } \\
\hline 1 & $\begin{array}{l}\text { Miller cycle - } \\
\text { high compr. } \\
\text { Ratio }\end{array}$ & $\begin{array}{l}\text { S.l. engine with displ. } \mathrm{V}_{\mathrm{d}}, \text { WOT, } \\
\text { Compr.Ratio=12, } \\
\text { ExpansionRatio=23 }\end{array}$ \\
\hline 2 & $\begin{array}{l}\text { Miller cycle - } \\
\text { low compr. } \\
\text { Ratio }\end{array}$ & $\begin{array}{l}\text { S.l. engine with displ. } \mathrm{V}_{\mathrm{d}}, \text { WOT, } \\
\text { Compr.Ratio=7.75, } \\
\text { ExpansionRatio=12 }\end{array}$ \\
\hline 3 & $\begin{array}{l}\text { Otto cycle - half } \\
\text { load }\end{array}$ & $\begin{array}{l}\text { S.l. engine with displacement } \mathrm{V}_{\mathrm{d}} \text {, at } \\
\mathrm{p}_{\text {intake }}=50 \mathrm{kPa} \text {, Compr.Ratio=12 }\end{array}$ \\
\hline 4 & $\begin{array}{l}\text { Otto cycle } \text { - half } \\
\text { displacement }\end{array}$ & $\begin{array}{l}\text { S.I. engine with displacement } \mathrm{V}_{\mathrm{d}} / 2, \\
\text { WOT, Compr.Ratio=12 }\end{array}$ \\
\hline
\end{tabular}

Table 1 - Comparison of 4 different engine concepts

The simulated cycles are four different ways of performing the 4-stroke engine work at similar (half) load. Engine 1 and 2 work as Miller cycle, the first one with an effective compression of 12 and the latter with an expansion ratio of 12 (or the geometric compression ratio $\varepsilon_{g}$ ), which gives an effective compression ratio of 7.75. Two engines working under the Otto cycle were also simulated, one working at half load but with the same geometric parameters and a second working at full load (WOT) but with just half of the displacement.

Using expression (4), for the engines 1 and 2, the values of $\sigma$ are respectively 1.917 and 1.55 (in order to get similar values for load).

For engine 4 the displacement used is half of the displacement of the other engines in order to simulate the same load $\left(\mathrm{V}_{\mathrm{d}} / 2\right)$. In all cases it is considered that the intake mixture is stoichiometric. The $p-V$ diagram of these 4 engines can be seen in Figure 17.

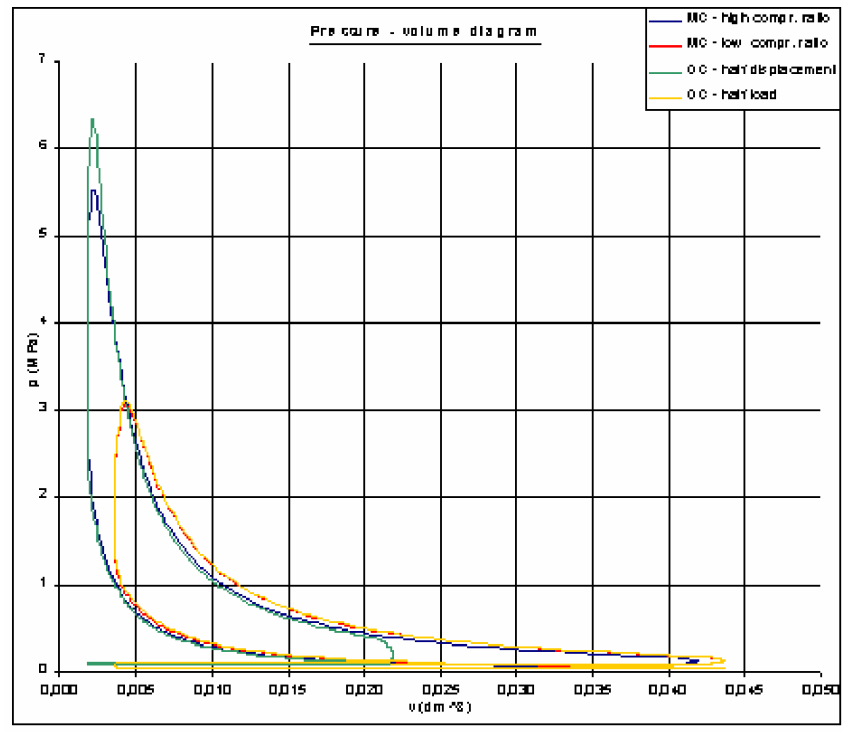

Figure 17 - p-V diagrams for the 4 engines cycle.

The thermal efficiencies obtained with this simulation $\left(\eta_{\text {indicated }}\right)$ and with the theoretical cycle calculation $\left(\eta_{\text {theoretic }}\right)$ for the several cycles are described in Table 2.

\begin{tabular}{|l|l|c|c|}
\hline \multicolumn{2}{|c|}{ Engine cycle } & $\eta_{\text {indicated }}$ & $\eta_{\text {theoretic }}$ \\
\hline 1 & Miller cycle - high compr. ratio & 0,407 & 0,704 \\
\hline 2 & Miller cycle - low compr.ratio & 0,350 & 0,625 \\
\hline 3 & & 0,325 & 0,602 \\
\hline 4 & Otto cycle - half load & & 0,630 \\
\hline
\end{tabular}

Table 2 - Efficiency results of the 4 different engine concepts

Referring to Figure 7 (eq.4.12), the value for thermal efficiency of an engine working as Miller cycle with a trapped compression ratio of 12 and a $\sigma$ of 1.7 , would be 0.695 and for the engine with a geometric compression ratio of 12 and a $\sigma$ of 1.7 , the theoretical thermal efficiency value was 0.62 (Figure 6, eq.4.11). For engine 3 , the theoretical study shows that the efficiency result for a $p_{1}$ of $50 \mathrm{kPa}$ would be 0.6018 (eq.2.14, 2.16).

However the values obtained with the indicated cycle simulation are very different from these. The main reasons for that discrepancy are the heat transfer between the combustion gases and the cylinder liner and the non-instantaneous combustion. This heat transfer will cause a decrease of temperature and pressure of those gases during the expansion stroke, which will result in 
less work supplied by the engine, and the noninstantaneous combustion leads to lower maximum pressure and temperature.

\section{COMPARING THE DIFFERENT ENGINES}

As expected, the engine using the Miller cycle with a trapped compression ratio of 12 (engine1) shows the higher value for efficiency, both in the theoretical approach and with the indicated cycle approach. The lower efficiency of the Otto cycle at half load (engine 3) was also expected, as the pumping losses (intake at lower pressure than exhaust) reduce the net work for the same heat of combustion. However, the reduction of efficiency comparing the indicated cycles $(-20 \%)$ is higher that those for the theoretical cycles $(-15 \%)$, showing that the indicated cycle is a better method of comparing different engine designs.

Comparing the Miller cycle with low trapped compression ratio (engine 2) with the Otto cycle with half displacement (engine 4) we can see that the latter engine has better efficiency. What we are comparing is an engine with fixed compression ratio but with variable valve timing with an engine where the displacement (e.g. number of working cylinders) can be changed (concept usually known as "displacement on demand"). The first engine is modelled by the Miller cycle with low trapped compression ratio (engine 2) and the variable valve system enables it to change the beginning of the intake stroke, therefore changing the load without incurring in pumping losses (the intake is at similar pressure than that of the exhaust). The latter engine is modelled by the Otto cycle with half displacement (half the cylinders working). The results seem to show that an engine where some cylinders can be disabled can achieve similar (but better) efficiency than an engine with variable valve events. However, the variable valve engine can change its angle of valve openings continuously and almost instantaneously, where the "displacement on demand" engine can only cut one cylinder at a time (not a continuous change).

The herein proven better engine (Miller cycle with high trapped efficiency-engine 1) is a "normal" spark ignition engine with the capability for variable valve events and variable compression. This engine should alter its load by changing the opening of the inlet valve, while changing the combustion chamber volume, so the trapped compression ratio should remain constant at the highest level limited by knock.

\section{CONCLUSIONS}

From the theoretical cycle analysis herein presented (comparing Otto, Diesel, Dual and Miller cycles at part load), it is clear that the most efficient cycle under light and part load conditions is the Miller cycle with fixed trapped compression ratio, particularly at very low loads (0.3 to 0.4 ), where it can achieve theoretical efficiencies approaching $73 \%$. In fact the engine using that cycle can be seen as an Otto cycle engine with admission always at atmospheric pressure (not throttled) and with an extension of the expansion stroke, so it takes advantage of the performance of the Otto cycle at full load (stoichiometric mixture) and the possibility of an extra expansion. This cycle can only be implemented in engines using variable valve timing and variable compression ratio. For very light loads, the final pressure is bellow atmospheric, which reduces efficiency. It is clear that this is the cycle that can have more chances of success in applications working frequently under part load. At the same time, this is a spark ignition engine cycle, with its distinctive smoothness and which can use a three-way catalyst. Although the Diesel and dual cycles have better efficiency than the Otto cycle at part load, they are required to be operated with compression ratios much higher than 25:1 to get similar efficiencies to the Miller cycle.

Some indicated cycle calculations presented in this paper showed that the Otto cycle with reduced displacement (but running at WOT in a "displacementon-demand" engine) has the potential of running at light load and making use of the high efficiency of the Otto cycle at full load, but only on an engine where some cylinders can be disabled. This engine has a slightly better efficiency than the Miller cycle with low compression ratio (in practice an Otto engine using a variable valve system) due to the fact that its maximum pressure and temperature are higher. However, when a Miller cycled engine with high compression ratio is used, its efficiency is much higher than any of the previously presented engines working at part load.

\section{ACKNOWLEDGMENTS}

Bernardo Ribeiro thanks the FCT and FSE (in the scope of QCA III) for the financial support given for his research activities.

\section{REFERENCES}

1. Ferguson, C.R. and Kirkpatrick, A.T.: Internal Combustion Engines, J.Wiley\&Sons, 2001.

2. Flierl, R. and Kluting, M., The Third Generation of Valvetrains-New Fully Variable Valvetrains for Throttle-Free Load Control, SAE 2000-01-1227, 2000

3. Drangel, H., Reinmann, R., Olofsson, E., The Variable Compression (Svc) and the Combustion Control (Scc) - Two Ways to Improve Fuel Economy and Still Comply With World-Wide Emission Requirements, SAE 2002-01-0996, 2002

4. Heywood, B.J.: Internal Combustion Engines Fundamentals, McGraw-Hill, 1988.

5. Hatamura, K. and Hayakawa, M.: A study of the improvement effect of Miller-cycle on mean effective pressure limit for high-pressure supercharged gasoline engines, JSAE Review 18, 1997. 


\section{CONTACT}

Jorge Martins is an Associated Professor at the Universidade do Minho at Guimaraes, Portugal, where he is head of the I.C. Engines Laboratory. He can be contacted on jmartins@dem.uminho.pt.

\section{NOMENCLATURE}

\section{VARIABLES}

$\mathrm{C}_{\mathrm{p}} \quad$ Specific heat at constant pressure

$\mathrm{C}_{\mathrm{v}} \quad$ Specific heat at constant volume

$\mathrm{m} \quad$ mass

P Pressure

Q Heat

R Universal gas constant

T Temperature

V Volume

W Work $\beta \quad$ Intake pressure ratio

$\varepsilon_{\mathrm{g}} \quad$ Geometric compression ratio

$\varepsilon_{\mathrm{tr}} \quad$ Trapped compression ratio

$\gamma \quad$ Specific heat ratio

$\eta \quad$ Efficiency

$\sigma \quad$ Expansion ratio

$\tau \quad$ Combustion rise pressure ratio

$\Phi$ fuel/air equivalent ratio

$\Psi \quad$ Isocoric/isotermic heat delivering ratio

\section{SUBSCRIPTS}

$1,2,3,4, \ldots$ $\mathrm{BDC}$

f

$g$

LHV

TDC

$\operatorname{tr}$

Reference points of the cycle Bottom Dead Center

fuel

Geometric

Lower Heating Value

Top Dead Center

Trapped 